Acta Protozool. (2017) 56: 149-160

www.ejournals.eu/Acta-Protozoologica

doi:10.4467/16890027AP.17.013.7494

PROTOZOOLOGICA

\title{
Cortical Localization of $\alpha$ - and $\gamma$-Tubulin and the Assembly of Cortical Microtubule Cytoskeleton in Hypotrichous Ciliate Euplotes eurystomus
}

\author{
Xin SHENG ${ }^{1,2^{*}}$, Yan SHENG ${ }^{3 *}$, Yuehua LIU ${ }^{1}$, Junhua WANG ${ }^{1}$ \\ ${ }^{1}$ Department of Biochemistry, Zunyi Medical University, Zunyi, Guizhou, China; ${ }^{2}$ School of Life Science, East China Normal \\ University, Shanghai, China; ${ }^{3}$ Laboratory of Basic Medical Morphology, Zunyi Medical University, Zunyi, , Guizhou, China \\ ${ }^{*}$ Those authors contributed equally to this work.
}

\begin{abstract}
This study aimed to investigate the assembly characteristics of ciliature and cortical microtubules and the localization of tubulins in different depths and regions of the cortex. The hypotrichous ciliates have closely arranged cilia and a highly complex microtubular system. Direct fluorescence and immunofluorescence labeling were used to observe ciliary organelles and cortical microtubular cytoskeleton in Euplotes eurystomus. An immunofluorescence analysis demonstrated that $\alpha$-tubulin localized to the ventral and dorsal ciliary organelles and their associated microtubules, while $\gamma$-tubulin localized to the basal bodies of ciliary organelles, macronuclear membrane, and excretory pore of a contractile vacuole in the interphase. A direct fluorescence analysis showed that the ciliature and cortical microtubules in the deep cortex were more clearly marked by fluorescent taxoid (FLUTAX). Interestingly, $\alpha$ - and $\gamma$-tubulins also colocalized to the ringlike ciliary base-associated microtubules of dorsal kineties. The short microtubular bundles between the bases of transverse cirri could be marked by FLUTAX and $\gamma$-tubulin rather than $\alpha$-tubulin, suggesting that tubulins in cortical microtubules in E. eurystomus varied, and the differentiation of cortical microtubules in the hypotrichous ciliate tended to be versatile. Also, during morphogenesis, $\gamma$-tubulin also localized to the base of ciliary primordium, where new basal bodies were formed, suggesting that the endocellular position of $\gamma$-tubulin in ciliates was related to basal bodies and regulated by the cell cycle. This study might help understand the assembly characteristics and tubulin composition of microtubules in different depths and regions of the cortex in hypotrichous ciliate E. eurystomus.
\end{abstract}

Key words: basal body, ciliature microtubular organelles, E. eurystomus, FLUTAX, immunofluorescence, $\gamma$-tubulin.

Abbreviations: fluorescent taxoid (FLUTAX), microtubule organizing centers (MTOCs), undulating membranes (UMs), polymerase chain reaction (PCR), adoral zone of membranelles (AZMs), frontal-ventral cirri (FVCs), transverse cirri (TCs), caudal cirri (CCs), left marginal cirri (LMCs), dorsal kineties (DKs), frontal-ventral and transverse cirri (FVTC), anterior longitudinal microtubules (ALMs), small membranelle bracket (SMB), posterior longitudinal microtubules (PLMs), peripheral microtubules (PMs), AZM primordium (AZMP), UM primordium (UMP), FVTC primordium (FVTCP).

Address for correspondence: Xin Sheng, Department of Biochemistry, Zunyi Medical University, Zunyi, Guizhou 563003, China; Email: xshengbio@163.com; Tel.: +86 18212136401; Fax: +86 2164085875 


\section{INTRODUCTION}

Microtubule is an important cytoskeleton in eukaryotes. It has gained immense attention owing to its multiple functions, such as maintaining cell morphology, intracellular material transportation, cell division, and so on (Elmendorf et al. 2003). Tubulin is the basal component of microtubules, which is assembled by $\alpha$ - $/ \beta$-tubulin heterodimers. Generally, the immunofluorescence labeling of $\alpha$-tubulin is used to observe dynamic changes in microtubules. In recent years, smallmolecule fluorescent labeling of microtubules is used. It involves the use of fluorescent taxoid (FLUTAX), a taxol derivative, which can specifically combine with $\alpha$-/ $\beta$-tubulin heterodimers. A small amount of FLUTAX can quickly and accurately label microtubular cytoskeleton (Arregui et al. 2002). Therefore, its affinity is higher than that of $\alpha$-/ $\beta$-tubulin antibody and can show more details of microtubular cytoskeleton (Evangelio et al. 1998; Díaz et al. 2000). Besides the cytoskeleton, a variety of organelles are assembled by microtubules, such as centrosome, spindle, cilia, and basal body. Cilia are organelles that are prominent on the surface of the cell and are composed of mainly ciliary axoneme, basal body, and root fibers. The basal body is located at the base of cilia, which originates from the centrosome. The root fibers are the microtubules around the basal body (Lynn and Small 1981).

Ciliates are unicellular eukaryotes with cilia that are the movement, trapping, and defense organelles. A ciliate contains an extremely complex microtubular system and various types of microtubule organizing centers (MTOCs). The cortex in the ciliate, also known as a pellicle, is a thin layer of plasmalemma covering the surface of ciliate. The basal bodies and ciliary baseassociated microtubules of ciliate are all anchored to the cortex. The microtubules in the cortex are highly differentiated and grouped into various types of lattice structure in order. Thus, the ciliate is an ideal model for research on microtubules and tubulin (Gaertig 2000). The hymenostomatida ciliates Tetrahymena and Paramecium are used to study the mechanism and regulation of microtubule assembly, and no less than 17 different cortical microtubule structures are found just in Tetrahymena thermophila (Libusová and Dráber 2006). In contrast, hypotrichous ciliate, which has a differentiation of dorsum and venter, contains much more complex ciliature and microtubular system compared with the hymenostomatida ciliate. The ventral cilia in hypotrichous ciliate are clustered to form the cirri and distribute in different regions of cortex according to a certain ciliary pattern. However, despite deep understanding about the microtubular assembly and MTOCs in Tetrahymena and Paramecium (Iftode et al. 2000; Shang et al. 2002, Iftode and Fleury-Aubusson 2003), the principal and regulatory mechanism of the differential assembly of ciliature and cortical microtubules in hypotrichous ciliate are poorly understood.

Although at least 10 kinds of tubulins have been discovered, an overwhelming majority of tubulins, such as $\delta$-, $\varepsilon_{-}, \zeta-$, and $\eta$-tubulins, have been found only in a few species at present, what is important is that Paramecium contains all the already discovered members (Marshall and Rosenbaum 2003). Thus, the microtubule and tubulins are implicated in the structure and function in ciliates. The $\gamma$-tubulin is ubiquitous and evolutionarily conserved in eukaryotes (Oakley and Oakley 1989). It is the core protein of MTOCs related to the initiation of microtubular assembly and replication of basal bodies (Moritz et al. 1995; Ruiz et al. 1999). The cellular localization of $\gamma$-tubulin is highly diverse, such as basal bodies, centrosome, spindle, and kinetochore (LajoieMazenc 1994; Shu et al. 1995; Scott et al. 1997; Binarová et al. 2000). In Tetrahymena, it is located mainly in the macronucleus, micronucleus, and basal bodies (Shang et al. 2002). In Paramecium, interference in the expression of this protein affects mainly the duplication and stabilization of basal bodies (Ruiz et al. 1999). However, a few reports are available about its location and difference from other tubulins in the hypotrichous ciliate, which has more complex MTOCs.

Euplotes is an evolutionarily advanced hypotrichous ciliate. Its cortical microtubular cytoskeleton was observed using a transmission electron microscope in a preliminary study. The results showed that it consisted of ciliature microtubules and nonciliated microtubules. The former included the ciliary rod, basal body and its accessory microtubules, and subsidiary microtubules of cilia. The latter comprised the leptos microtubule nets in the dorsal and ventral cortex, oblique microtubules in the dorsal cortex, and longitudinal microtubules ( $\mathrm{Gu}$ et al. 2003). FLUTAX and anti- $\alpha$ - and $\gamma$-tubulin antibodies were used to decorate the cilia and microtubular cytoskeleton in the present study to further understand the assembly characteristics of microtubules and tubulin composition in different depths and regions of the cortex in hypotrichous ciliate E. eurystomus, as well as the changes in microtubules of cortical cilia during morphogenesis. The results may provide some data for 
further studies on the mechanism of the differential assembly of cortical microtubular cytoskeleton in hypotrichous ciliates.

\section{MATERIALS AND METHODS}

\section{Materials}

The ciliate E. eurystomus was collected from Dianshan Lake $\left(31^{\circ} 05^{\prime}\right.$ to $19.91^{\prime \prime} \mathrm{N}, 120^{\circ} 55^{\prime}$ to $\left.39.11^{\prime \prime} \mathrm{E}\right)$ in Shanghai. Collected samples were acclimatized to laboratory conditions and then grown in the incubator [temperature: $25^{\circ} \mathrm{C}$, light: $12 \mathrm{~h}(6: 00 \mathrm{a} . \mathrm{m}$. to $6: 00$ p.m.), $\mathrm{pH}$ 7.0-7.2]. It was cultured in filtered pond water from a lake and fed the flagellate Chilomonas paramecium preserved in the laboratory.

\section{Immunocytochemistry}

The cells were permeabilized in PHEM buffer [piperazine-1,4bisethanesulfonic acid, $60 \mathrm{mM}$; 4-(2-hydroxyethyl)-1-piperazineethanesulfonic acid, $25 \mathrm{mM}$; ethylenediaminetetraacetic acid, $10 \mathrm{mM}$; $\left.\mathrm{MgCl}_{2} 2 \mathrm{mM}\right]$ with $0.5 \%$ saponin for $2 \mathrm{~min}$, followed by fixation in $4 \%$ paraformaldehyde for $30 \mathrm{~min}$. The cells were then rinsed with PHEM buffer followed by phosphate-buffered saline supplemented with $3 \%$ bovine serum albumin. This buffer was used for all subsequent immunodetection steps. The cells were incubated for $1 \mathrm{~h}$ at room temperature with primary antibodies: anti- $\alpha$-tubulin and anti- $\gamma$-tubulin monoclonal antibodies (mouse, $1: 1000$ ) (Sigma-Aldrich, USA, T5198, T6557). They were subsequently rinsed three times, incubated for $1 \mathrm{~h}$ with fluorescein isothiocyanate-labeled anti-mouse immunoglobulin G antibody (Dingguo, China), and then rinsed three times after incubation. Ghosts were mounted in Citifluor (Citifluor Ltd, Great Britain) and observed under a fluorescence microscope (Olympus BX61, Japan).

\section{Direct fluorescence microscopy with FLUTAX}

The cells were first collected, fixed with $1 \%$ paraformaldehyde for $3 \mathrm{~min}$, and washed with PHEM buffer for $5 \mathrm{~min}$ to avoid the disintegration and deformation of cells because Euplotes was sensitive to the osmotic pressure. They were then permeabilized in $0.5 \%$ Triton X-100 for 2 min and washed with PHEM for $5 \mathrm{~min}$. Next, the cells were stained with $1 \mu \mathrm{M}$ FLUTAX-2 (Molecular Probes Inc., OR, USA) for $10 \mathrm{~min}$ and washed with $0.01 \mathrm{M}$ PBS for $5 \mathrm{~min}$. Finally, they were transferred onto a slide covered with poly-L-lysine $(1: 10)$ and observed under a fluorescence microscope (Olympus BX).

\section{$\boldsymbol{\gamma}$-Tubulin gene amplification}

Macronuclear DNA of E. eurystomus was prepared according to the method described by Sambrook et al (1992). The $\gamma$-tubulin gene was then amplified by polymerase chain reaction (PCR) with macronuclear DNA as a template and the oligonucleotides 5'-ATGCCAAGAGAGATCATTAC-3' as the forward primer and 5'-TACTGAATATTGCTGAATTTTGGAGG-3' as the reverse primer, which was reported in Euplotes crassus by Tan and Heckmann (1998), under the following conditions: denaturation for $4 \mathrm{~min}$ at $94^{\circ} \mathrm{C}$ followed by 30 cycles of amplification for $45 \mathrm{~s}$ at $94^{\circ} \mathrm{C}, 45 \mathrm{~s}$ at $46^{\circ} \mathrm{C}$, and $1 \mathrm{~min}$ at $72^{\circ} \mathrm{C}$, after a final extension of $7 \mathrm{~min}$ at $72^{\circ} \mathrm{C}$, and then holding at $4^{\circ} \mathrm{C}$.

The amplified products were analyzed by agarose gel electrophoresis and then sequenced (Applied Biosystems, NY, USA).

\section{RESULTS}

\section{Immunofluorescent localization of $\alpha$-tubulin in E. eurystomus}

The ventral cilia of E. eurystomus were formed by the adoral zone of membranelles (AZMs), one oral cirrus (OC), nine frontal-ventral cirri (FVCs), five transverse cirri (TCs), two caudal cirri (CCs), and two left marginal cirri (LMCs) (Fig. 1A). However, the dorsal cilia were formed by $8-10$ columns of dorsal kineties (DKs) (Fig. 1B). The distribution of cilia and accessory structures could be clearly observed by specifically labeling the $\alpha$-tubulin in Euplotes. The results showed that the ventral ciliary organelles in E. eurystomus were labeled with hyperfluorescence. These cilia included AZMs, undulating membranes (UMs), frontal-ventral and transverse cirri (FVTC), and LMC. Also, ciliary base-associated microtubules under the pellicle were labeled, such as the anterior longitudinal microtubules (ALMs) of TC and the posterior longitudinal and transverse microtubules of FVC (Fig. 2A). Similarly, the DKs and their ringlike ciliary base-associated microtubules also could be marked (Fig. 2B). In the deep dorsal cortex, the dargyrome was clearly marked with further extraction by increasing the acting time of permeation reagent during immunohistochemical analysis. Two rows of dargyrome grids were present between the columns of DK. The grids were polygonal in shape, and the microtubules were shared between the adjacent grids (Fig. 2C). During morphogenesis, new columns of DK primordium could be observed in the central part of cell, which extended forward and backward to gradually displace the old DKs during cell division and finally formed new DKs of proter and opisthe (Fig. 2D).

\section{Direct fluorescent labeling of the cortical micro- tubule cytoskeleton with FLUTAX}

As FLUTAX is a small-molecule marker of microtubules, it can rapidly penetrate the membrane and stably combine with microtubules. Therefore, the microtubular cytoskeleton in the deep cortex could be displayed using FLUTAX. In the interphase, besides the dorsal and ventral ciliary organelles and their base-associated microtubules (Fig. 3A), the microtubule fasciculus extended 


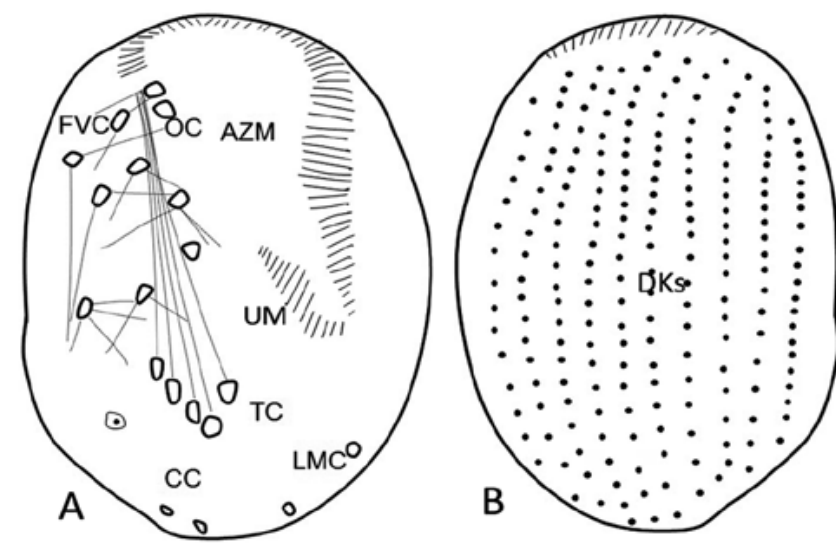

Fig. 1. The permutation pattern of ciliary organelles in the ventral and dorsal of E. eurystomus cells (A, B). (A) The ventral ciliary pattern of E.eurystomus, $(\mathbf{B})$ the dorsal ciliary pattern of E.eurystomus. (AZM: adoral zone of membranelles, OC: oral cirri; UM: undulating membranes, FVC: frontal-ventral cirri, TC: transverse cirri, CC: caudal cirri, LMC: left marginal cirri DK: dorsal kineties).

from the base of small membranelle bracket (SMB); the microtubules in the adoral rib and UM base-associated microtubules could also be observed (Fig. 3B). The ALM, posterior longitudinal microtubules (PLMs), $\mathrm{TM}$, and peripheral microtubules (PMs) of FVC could be equally observed (Fig. 3A). Moreover, besides the anterior-posterior microtubules of TC, some short microtubular bundles extending from the base of TC to the front cortex could be labeled by FLUTAX. They were connected by lateral microtubules (Fig. 3C). In the deep cortex, latticed microtubules covering the whole dorsal and ventral cortex could be observed (Fig. 4A, 4B), especially around the AZMs. In addition, some longitudinally or obliquely arranged microtubules could also be displayed (Fig. 4B, 4C). What is noteworthy was that the dargyrome in the dorsal cortex could be slightly displayed (Fig. 4D); although it was not obvious, it could be observed in almost all the cells.
During morphogenesis, the genesis of each ciliary organelle occurred in temporal and spatial orders. The AZM primordium (AZMP) first positioned on the left side of old AZM, and then the UM primordium (UMP) originated from the AZMP. When the latter developed into a water drop shape, the end bent to the right side and separated to form the UMP (Fig. 5A). The FVTC primordium (FVTCP) followed among the old FVCs and arranged in a model of 3-3-3-2-2 from left to right (Fig. 5B). Next, the adoral cirri of opisthe developed from the front of UMP, while that of the proter developed at the margin of adoral rib. The LMCs primordium appeared near the AZM and broke into two marginal cirri of descendants (Fig. 5C). Also, with the occurrence of ventral cilia, the ciliary base-associated microtubules formed in order. The ALM of FVTCPs were initiated during the formation of the latter and elongated in the corresponding direction (Fig. 5D). It was worth noting that the old cirri and their ciliary base-associated microtubules did not disintegrate until the formation of new proter and opisthe (Fig. 5A-D, arrow).

\section{$\gamma$-Tubulin gene amplification from the macronucle- us and immunofluorescent localization of $\gamma$-tubulin in E. eurystomus}

Some Euplotes have two different $\gamma$-tubulin genes, $\gamma$-PT1 and $\gamma$-PT2. Thus, the proteins encoded by them have different cellular localization. The $\gamma$-tubulin gene was amplified from the macronucleus by PCR to identify the types of $\gamma$-tubulin in E. eurystomus, and the results of sequencing showed that the sequence was $1450 \mathrm{bp}$ long. The sequence was aligned with those of five other Euplotes, and their similarity was more than $80 \%$. These Euplotes were E. focardii, E. crassus, E. aediculatus, E. octocarinatus, and E. crassus. Their similarity with the $E$. aediculatus was as high as $93 \%$. This gene was found to be highly conserved among species.

Immunofluorescence showed that $\gamma$-tubulin localized mainly to the basal bodies of cilia in the interphase,

\footnotetext{
Fig. 2. (A-D) Projection of optical section passing through the ventral and dorsal surfaces of E. eurystomus cells decorated with the $\alpha$-tubulin antibody. Scale: $20 \mu \mathrm{m}$. (A) The $\alpha$-tubulin antibody was located at the ventral ciliary organelles and their ciliary base-associated microtubules (AZM: adoral zone of membranelles, UM: undulating membranes, FVC: frontal-ventral cirri, TC: transverse cirri, CC: caudal cirri, LMC: left marginal cirri; white arrow shows the posterior longitudinal microtubules of TCs; black arrow shows the anterior longitudinal microtubules of FVCs). (B) Eight rows of DKs are clearly marked, and a cyclic annular accessory microtubule at the base of DKs could also be observed (white arrow in the enlarged graph) (DKs: dorsal kineties). (C) The $\alpha$-tubulin antibody was also located at the dargyrome in the dorsal cortex. Each mesh was a hexagonal structure composed of microtubules (arrows). (D) The primordium of DKs in the middle of the cell (arrow).
} 
Cortical Localization of $\alpha$ - and $\gamma$-Tubulin $\mathbf{1 5 3}$

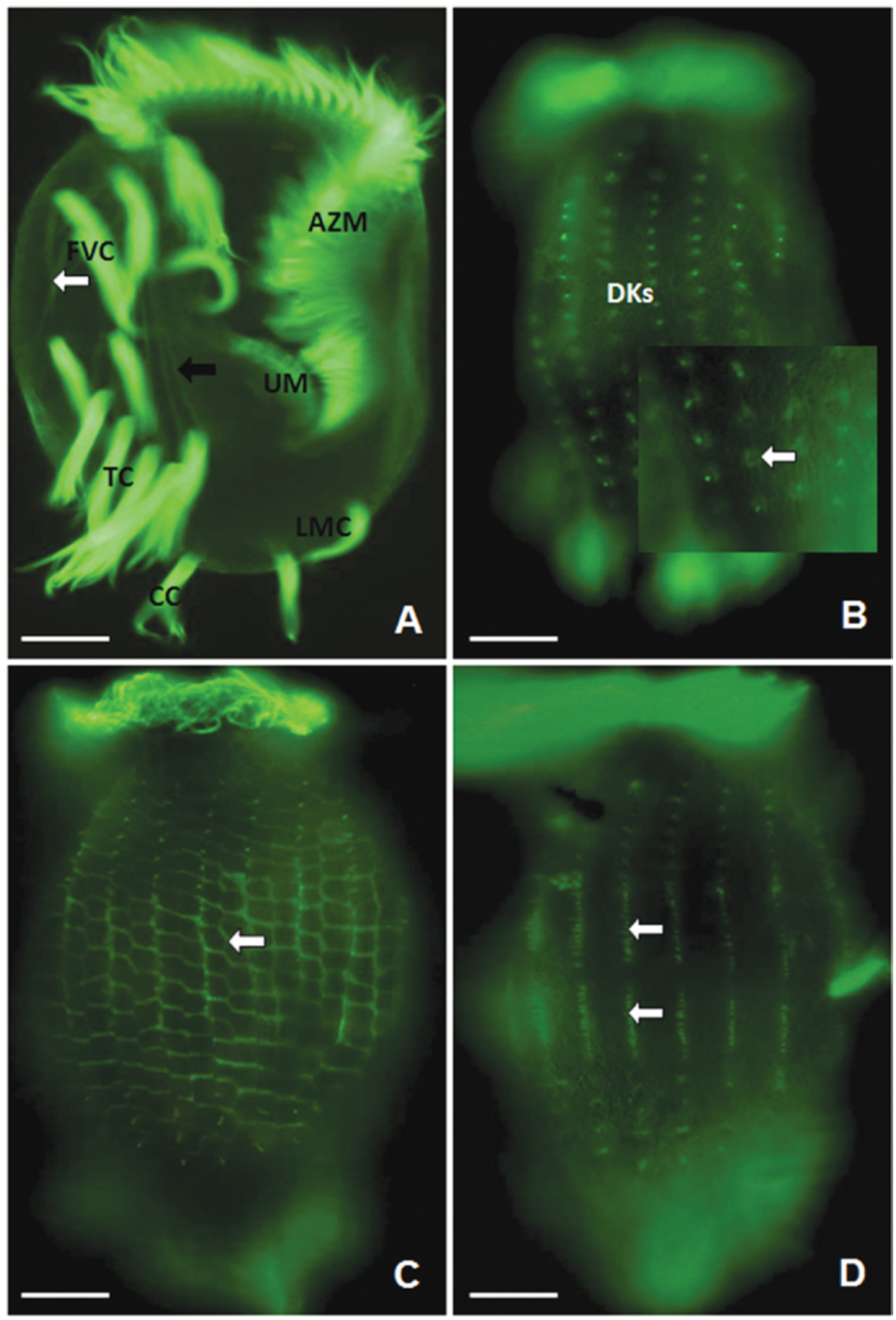



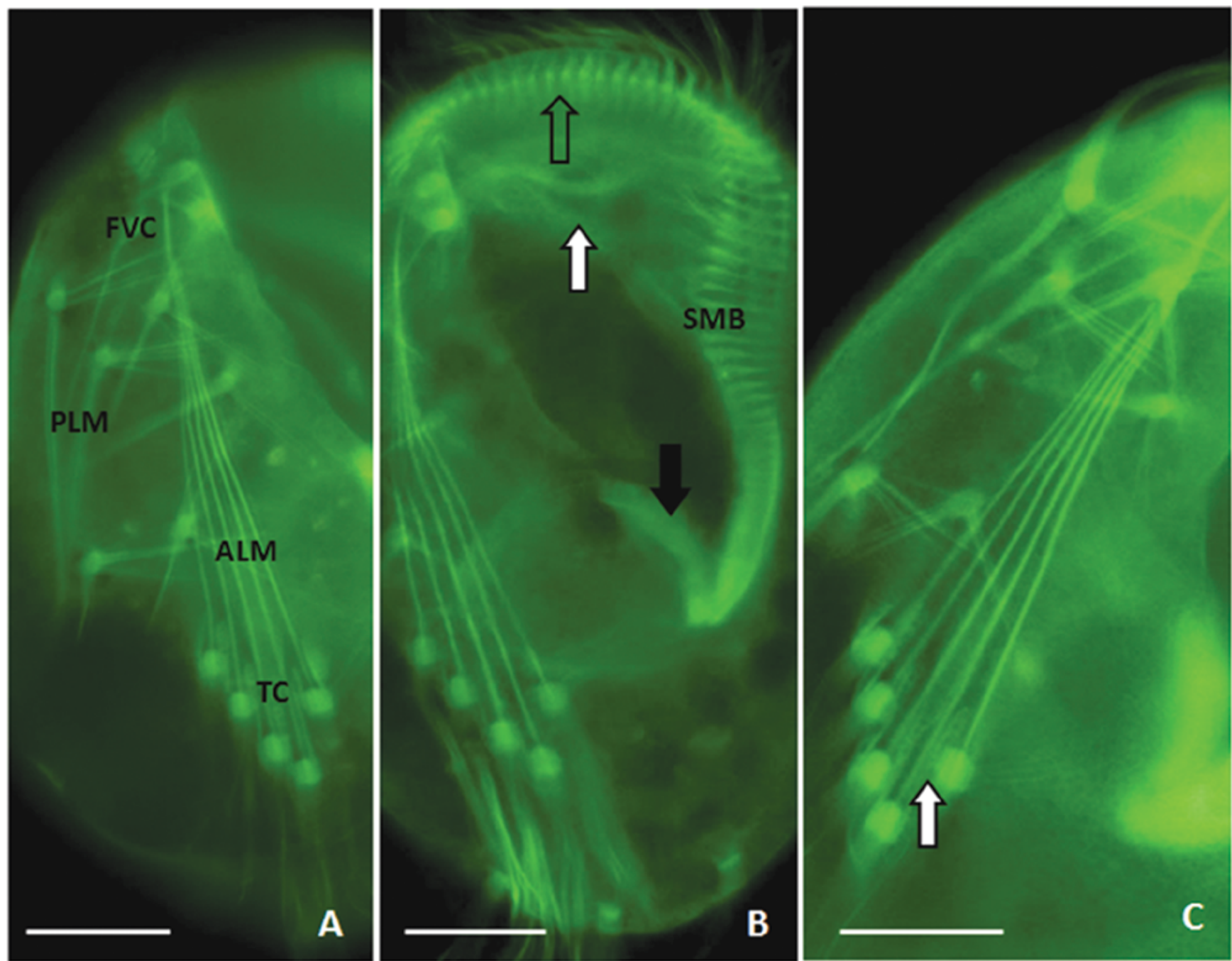

Fig. 3. (A-C) Projection of optical section passing through the ventral surface of E. eurystomus cells decorated with the FLUTAX. Scale: $20 \mu \mathrm{m}$. (A) All the ventral ciliary organelles, and especially their base-associated microtubules, were strongly and clearly stained by FLUTAX (ALM: anterior longitudinal microtubules; PLM: posterior longitudinal microtubules; TM: transverse microtubules; PM: peripheral microtubules). (B) The microtubules associated with the adoral ciliary organelles were also marked by FLUTAX (SMB: small membranelle bracket; hollow arrow shows the microtubule fasolculus extending from the base of SMB; white arrow shows the microtubules in the adoral rib; black arrow shows the UM ciliary base-associated microtubules). (C) The FLUTAX decorated the short microtubular bundles between the bases of TCs (arrow).

which contained the SMB of AZM, FVTC, and DKs (Fig. 6A and 6C). Furthermore, this protein was observed at the ringlike attached microtubules around the basal bodies of DKs (Fig. 6C, arrow). The short microtubular bundles between the base of TCs and the excretory pore of contractile vacuole could also be labeled (Fig. 6C). During morphogenesis, besides the basal body and accessory microtubules of old cilia, $\gamma$-tubulin also located to the FVTCP (Fig. 6B). The macronucleus with a shape of " 3 " could also be labeled through deep extraction to remove most of the structures of the cortex (Fig. 6D).

\section{DISCUSSION}

\section{Differentiation of the cortical microtubule in hypo- trichous ciliate tended to be versatile and functional}

The cortical microtubular cytoskeleton is the main component of the cortex in protozoa. This novel study showed that the cortical microtubular cytoskeleton had a variety of nonciliated microtubules in E. eurystomus, and obvious differences existed between the dorsum and venter. Similarly, Gu et al. (2003) observed longitudinal 

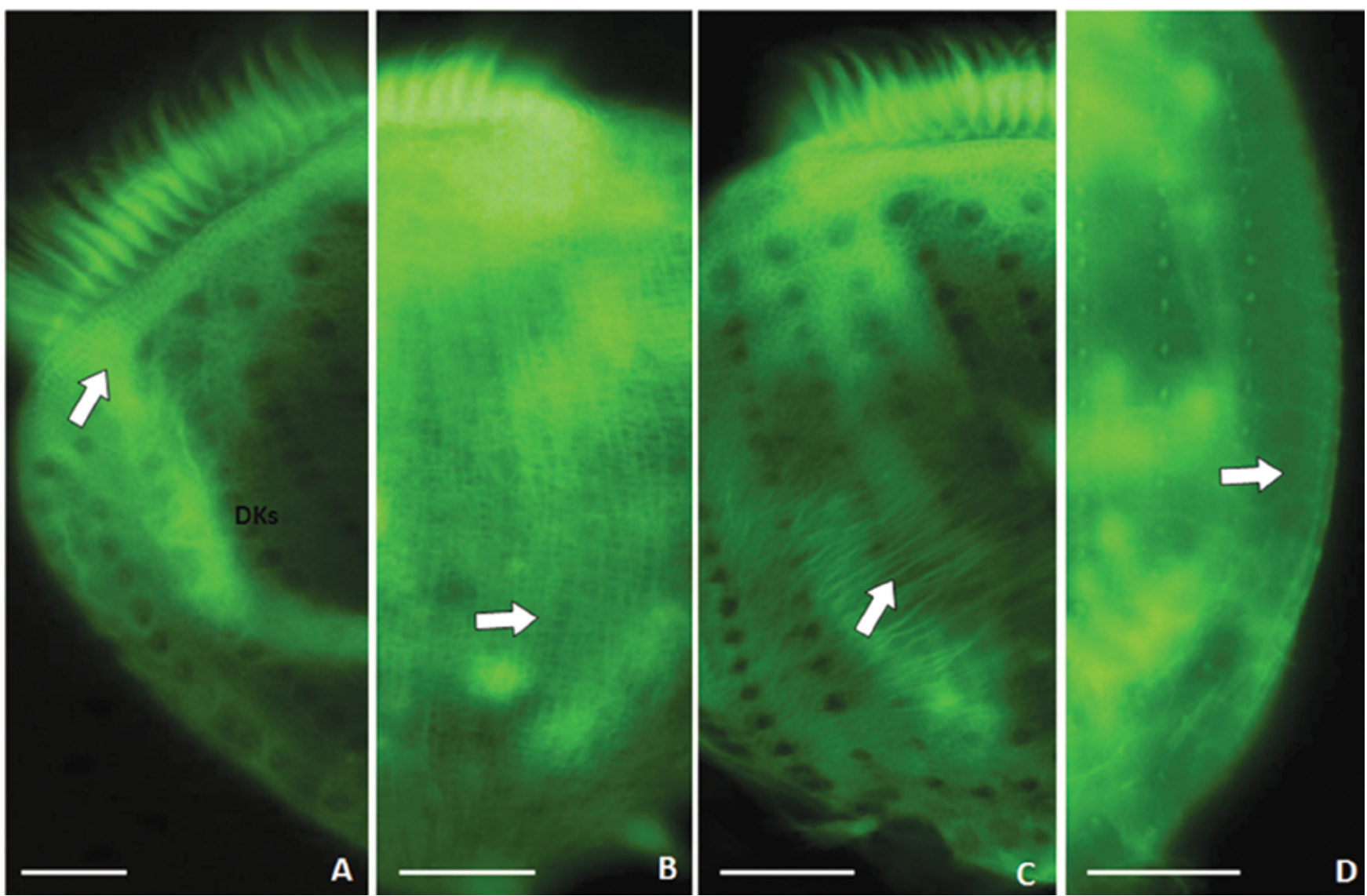

Fig. 4. (A-D) Projections of the optical sections passing through the dorsal cortex of E. eurystomus cells decorated with FLUTAX. Scale: $20 \mu \mathrm{m}$. (A) The leptos microtubular nets covered the dorsal cortex (arrow). (B) The longitudinal microtubules in the dorsal cortex (arrow). (C) The oblique microtubules in the dorsal cortex (arrow). (D) The dargyrome was faintly stained by the FLUTAX.

and spherical fibers, and fibers in the deep cortex bathy fibers below the pellicle, except for the ciliary cytoskeleton and its subsidiary fibers, using an electron microscope in E. harpa. However, these structures have not been reported in other ciliates to date. Thus, these nonciliated microtubules are unique in Euplotes. In contrast, the cortical microtubular cytoskeleton in T. pyriformis is much simple and undifferentiated (Allen 1967). Although the cortical microtubular cytoskeleton in Paramecium is slightly more complex and differentiated into regular regions, the dorsum and venter are not differentiated. Only in hypotrichous ciliates, the ventral ciliary cytoskeleton and its accessory microtubular structure located in the cortex are different (Gu 1991). It is thus clear that the differentiation of cortex in Euplotes is much more complex. Furthermore, the present study showed that the assembly of nonciliated microtubules was obviously different in different cortical regions, which was netlike, longitudi- nal, or oblique. Its structural and functional complexity in different cortical regions indicated that this phenomenon was related to functional differentiation.

Although the principle of microtubular assembly is already clear, the regulatory mechanism of the differential assembly of microtubules in different subcellular structures or cells remains a mystery because the present study focused mainly on the mechanism of microtubular assembly and its correlation with disease development. Only a few reports are available about the influence of taxol on microtubular assembly; they showed that the transverse microtubules of cilia disappeared, and the longitudinal microtubules were not affected when the microtubule assembly was inhibited by taxol (Kovács et al. 2007). Garreau de Loubresse et al. further studied the function of $\gamma$-tubulin in Paramecium using RNAi and found that its inactivation led to the deficiency of C-tubule in all the basal bodies but did 

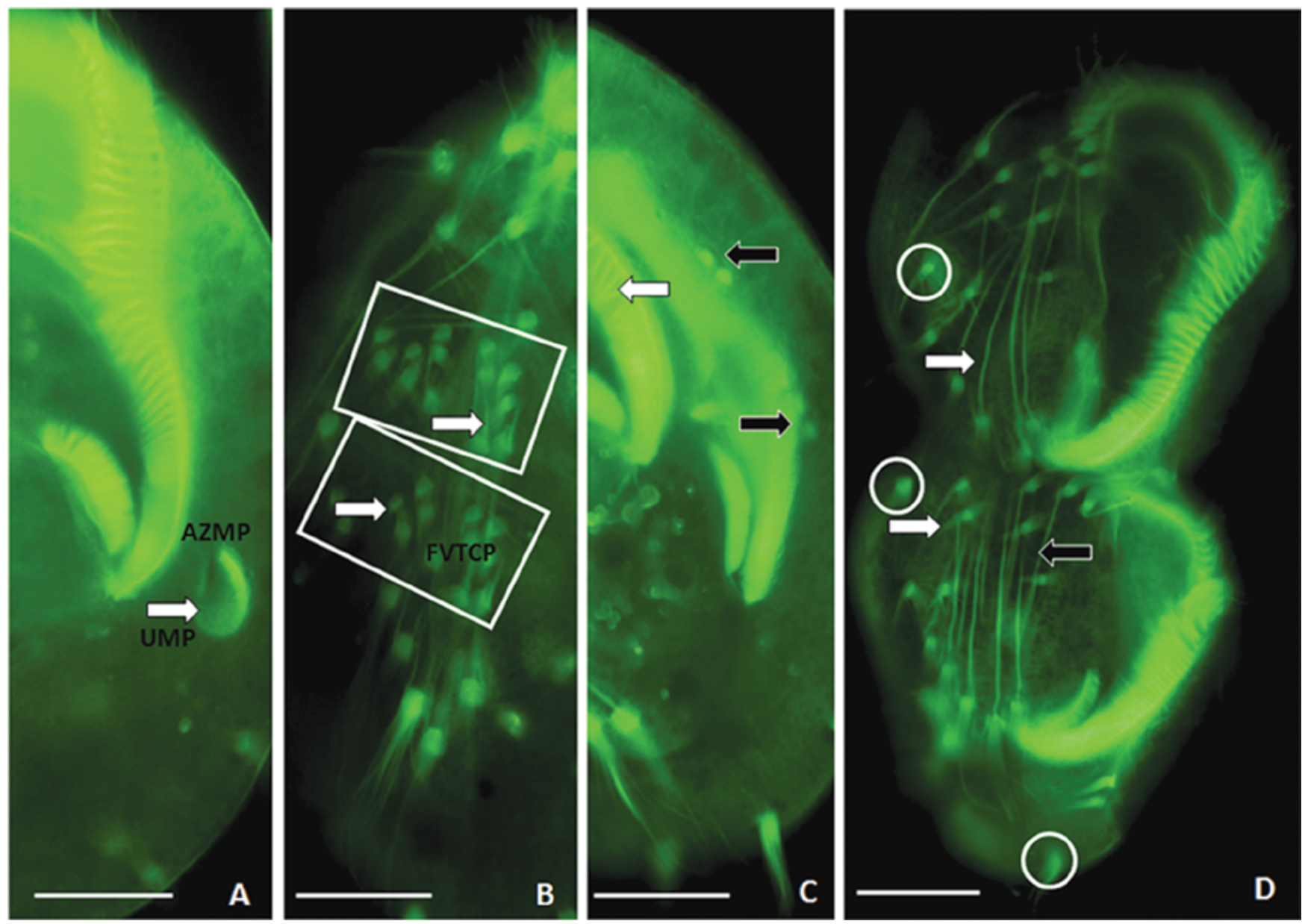

Fig. 5. (A-D) Projections of the optical sections passing through the ventral surface of E. eurystomus cells in mitotic phase decorated with FLUTAX. Scale: $20 \mu \mathrm{m}$. (A) The AZM primordium appeared at the bottom-left of old AZM in the early stage of morphogenesis. (AZMP: adoral zone of membranelles primordium; UMP: undulating membrane primordium; arrow shows the UMP originated from the right side of AZMP). (B) The pattern of FVTC primordia was 3-3-3-2-2 from left to right, shown in a box (FVTCP: frontal-ventral-transverse cirri primordium; arrows show the blastema of ALM and PLM originating from the base of FVTCPs). (C) The AZM and UM of proter inherited the olds (white arrow), and those of opisthe were generated from the AZMP (black arrows show the primordium of the left marginal cirri). (D) Some old ciliary organelles still existed until the separation of the proter and opisthe (white arrows show the neonatal ALM and PLM; black arrows show the residual ALM; some old cirri are shown in the circle).

Fig. 6. (A-D) Projection of optical section passing through the ventral and dorsal surfaces of E. eurystomus cells decorated with the $\gamma$-tubulin antibody. Scale: $20 \mu \mathrm{m}$. (A) The $\gamma$-tubulin antibody strongly decorated all the ciliary bases, the short microtubular bundles between the bases of TCs (white arrow) and the ostium of the contractile vacuole (black arrow). (B) All the basal bodies of ciliary organelles and ciliary primordium in the mitotic phase cells were specifically decorated (white arrows show the FVTCP bases; black arrow shows the AZMP bases). (C) The $\gamma$-tubulin antibody also strongly decorated the DKs associated microtubules (arrow). (D) The $\gamma$-tubulin antibody was also located on the surface of macronucleus (arrow).

not influence ciliogenesis (Loubresse et al. 2001). This did not directly affect the duplication of basal bodies but could disturb the cortical cytoskeleton structure and gradually caused mislocation and deficiency of basal bodies. Sheng et al. (2011) also demonstrated that interrupting the expression of $\gamma$-tubulin could result in the deficiency of some cortical nonciliated microtubules in Euplotes. Although this tubulin is an MTOCs-associated protein that participates in the initiation of microtubular assembly, its concrete function in the stabilization of cortical microtubules remains to be further studied. 


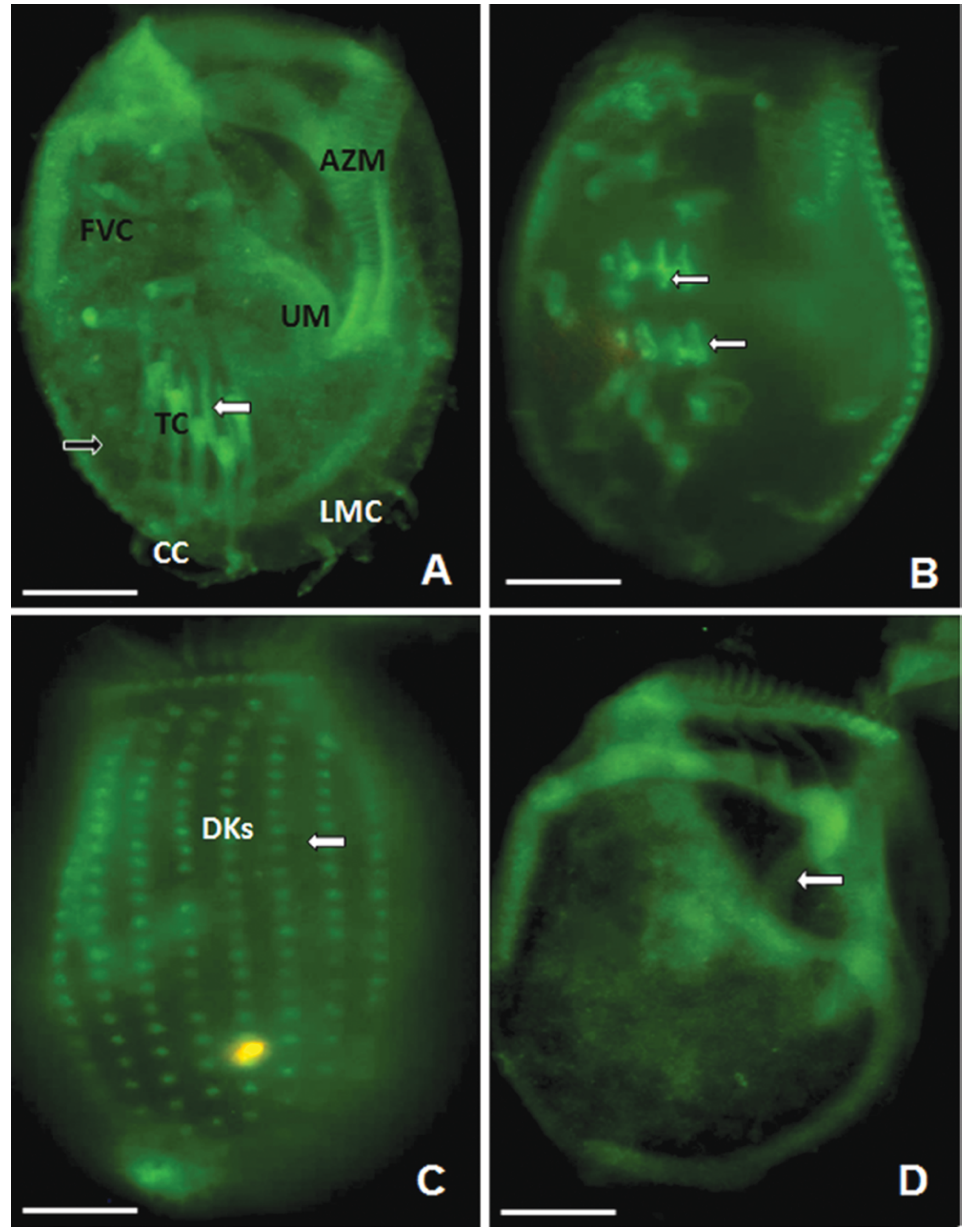


Types of tubulins forming the cortical microtubules in E. eurystomus were diverse

Compared with the traditional argentoproteinum, immunofluorescent labeling is more specific on the display of a microtubule and its genesis. Moreover, the antibody labeling technique solves the problem of the simultaneous display of multiple antigens. Olins et al. (1989) labeled the tubules in Euplotes using anti-glutamyl and tyrosyl tubulin antibodies. The results showed that these antibodies distributed in different cellular areas; the former located mainly to the cirri, pellicle, and around the macro- and micronuclei, and the latter in the base of cirri and the pellicle. FLUTAX and anti- $\alpha$ and $\gamma$-tubulin antibodies were used in the present study to label the microtubular cytoskeleton in E. eurystomus. The FLUTAX direct fluorescence labeling relied on the combination with the special site in the GTP hydrolysis region of $\beta$-tubulin. It could selectively label the already assembled microtubules rather than the nonassembled microtubulin dipolymers. The comparison of the results of the aforementioned three staining methods revealed that they could specifically display different ciliary organelles and cortical microtubules. In the ventral cortex, the microtubules of ciliary organelles and their base-associated microtubules could all be labeled by FLUTAX and anti- $\alpha$-tubulin antibody. Besides, the DKs and dargyrome in the dorsal cortex could also be labeled by FLUTAX. It was thus clear that these structures, acting as the cortical microtubular cytoskeleton system, were composed of mature assembled microtubulin dipolymers.

It was important that the ringlike attached microtubules around the DK basal bodies could be labeled by $\alpha$ - and $\gamma$-tubulin antibodies, but could not be labeled by FLUTAX. It indicated that this structure belonged to the basal body-associated microtubules. On the contrary, although the FLUTAX could specifically combine with microtubules, some differences were found between the staining of FLUTAX and anti- $\alpha$ tubulin antibody. It was reported that the two markers were used to stain the cortical microtubules in Tetrahymena, and both could be the specific markers for longitudinal microtubules, adoral and body ciliatures, bathy fibers, and the ostium of contractile vacuole, but the horizontal microtubules could not be labeled by FLUTAX. For the labeling of adoral ciliatures, FLUAX was more intense (Kovács et al. 2007). As FLUTAX was not able to label the unassembled microtubules, one possibility was that the microtubulin dipolymers comprising these structures might not have assembled yet. Another possibility was that although these microtubules were composed of assembled microtubulin dipolymers, they were still not labeled because the binding site of FLUTAX was covered by the post-translational modifications of tubulin. Furthermore, no such ringlike attached microtubules were found in the base of new DKs during morphogenesis. The main component of the microtubular scaffold around the basal bodies was the $\alpha / \beta$-tubulin heterodimers (Lechtreck and Geimer 2000), and the $\gamma$-tubulin was found mainly in the lumen and proximal end of basal bodies (Fuller et al. 1995). Moreover, significant differences were found among the different parts of basal bodies in the tubulin localization (Kilburn et al. 2007). It demonstrated that the ringlike attached microtubules around DKs were composed of a variety of tubulins, and assembled after the position of new ciliatures.

The excretory pore of the contractile vacuole was similar to the ringlike structures mentioned earlier and hence could be labeled by the anti- $\gamma$-tubulin antibody and FLUTAX. Interestingly, this structure could not be observed all the time, and all the labeled pores were in the open state. The present study showed that this pore was composed of various proteins with a diverse function. However, whether its contraction is related to the assembly and depolymerization of microtubules has not been reported. As early as in the 1980s, this structure was observed by silver staining, and some ribbonlike fibers were related to the contraction around the pore (Zhu 1984). This study showed that the excretory pore of the contractile vacuole belonged to the cortical microtubules and was composed of at least two types of tubulins. These tubulins may play some roles in contraction.

\section{Endocellular position of $\gamma$-tubulin in ciliates was consistently related to the basal bodies and regulat- ed by the cell cycle}

$\gamma$-Tubulin is thought to be the marker of MTOCs (Lajoie-Mazenc et al. 1994; Klotz et al. 2003). The present study showed that this protein was localized mainly to the basal bodies of cilia in the interphase, which contained the SMB of AZM, FVTC, and DKs, and macronucleus. Similarly, it was also located in the basal body, micro-/macronuclear membrane, and the excretory pore of the contractile vacuole in E. octocarinatus (Liang et al. 1996). Marziale et al. (2008) compared the localization of two hypotypes, $\gamma$-T1 and $\gamma-\mathrm{T} 2$, of this protein during morphogenesis in E. focardii. The results showed that $\gamma$-tubulin was always related to the 
basal bodies in the cell cycle, and also pitched in the DKs and the vessel cirri in the interphase. This phenomenon has also been reported in Paramecium (Klotz et al. 2003). Therefore, $\gamma$-tubulin is connected mainly with the basal bodies in protozoans. Moreover, the present study indicated that this protein was also located in the ringlike ciliary base-associated microtubules around basal bodies of DKs and the subsidiary microtubules in the base of TCs in E. eurystomus, which had been not reported in Euplotes. Probably one to several genes exist for this protein in different species. In some Euplotes, this protein usually has two different genes, $\gamma$-PT1 and $\gamma$-PT2 (Liang and Heckmann 1993; Tan and Heckmann 1998, Marziale et al. 2008). The $\gamma$-tubulins expressed by polygenes possess different electrophoretic mobilities and sedimentation coefficients, and accordingly are located at different MTOCs (Tan and Heckmann 1998). Therefore, $\gamma$-tubulin was amplified from the macronuclear genome in E. eurystomus, and just one gene was obtained. The gene sequence alignment indicated that its homology with that of E. aediculatus ( $\gamma$-PT, Y09551.1) was as high as 93\%. Although just one $\gamma$-tubulin gene was amplified, it was not known how many $\gamma$-tubulin genes were present in E. eurystomus without genome sequence. Hence, whether the localization of this protein in different regions is dependent on the genotype or whether differences exist in the protein modification level needs further investigation. Also, the localization of this protein at the new basal bodies occurs during morphogenesis. In summary, it participates in the formation of new basal bodies and is necessary for its replication. It is certain that $\gamma$-tubulin is consistently related to the basal body in ciliates, and its endocellular position is regulated by the cell cycle.

\section{Some connections existed between the old and new cilia in Euplotes during morphogenesis}

The connection between old and new cilia in ciliates during morphogenesis has gained extensive attention in recent years. Ciliogenesis involves the assembly of basal body and its localization in the cell membrane. Numerous studies have proved that the basal body has the function of self-replication in ciliates; the new structure is formed in the vicinity of the old one at a certain angle. The old structure acts as a template during the replication of basal body and has the function of orientation and positioning for the new one (Beisson and Wright 2003). In Tetrahymena and Paramecium, the replication and localization of basal body occur in the cortex. Usually, the assembly of new basal body occurs in the central part of cell, and it originates in the front of the old one to form a basal body pair. When the new one matures, it migrates to the front of the cell and is located in front of the row of the old one (Allen 1969; Iftode and Fleury-Aubusson 2003). Furthermore, some reports revealed that tubulin pools provide tubulin for the formation of microtubules during this process, and the pool derives from old microtubules, which are depolymerized (Oz et al. 2012). In Pseudourostyla crista$t a$, the genesis of the microtubules of L/RMC is accompanied by the disintegration of the old FVC. However, the FC, TC, and RMC in the nonprimordial area show no changes over a long time. Thus, the old ciliary structures in the primordial area contribute to the regional location for new cilia (Zhou et al. 2008). It is also reported in Paraurostyla weissei (Lou et al. 2007). The present study indicated that FVTCP originated between the old FVC and TC in E. eurystomus, and the old cirri did not disintegrate in the early stage. The ventral cirri first disintegrated along with the differentiation and migration of FVTCP, followed by some TC. Still some old FTC and their base-associated microtubules were found until the formation of cleavage furrow. Thus, the old ventral ciliary organelles and their base-associated microtubules might provide some tubulin materials for the formation of new ciliary structures and play some roles in the position of ciliary primordium.

Acknowledgment. This work was supported by grants from the National Natural Science Foundation of China (NSFC-31360278 and NSFC-31760616).

\section{REFERENCES}

Allen R. D. (1967) Fine structure, reconstruction and possible fuctions of components of the cortex of Tetrahymena pyriformis. $J$. Eukaryot. Microbiol. 14: 553-565

Allen R. D. (1969) The morphogenesis of basal bodies and accessory structure of the cortex of the ciliated protozoan Tetrahymena pyriformis. J. Cell Biol. 40: 716-733

Arregui L., Muñoz-Fontela C., Serrano S., Barasoain I., Guinea A. (2002) Direct visualization of the microtubular cytoskeleton of ciliate protozoa with a fluorescent taxoid. J. Eukaryot. Microbiol. 49: 312-318

Beisson J., Wright M. (2003) Basal body/centriole assembly and continuity. Curr. Opin. Cell Biol. 15: 96-104

Binarová P., Cenklová V., Hause B., Kubátová E., Lysák M., Dolezel J., Bögre L., Dráber P. (2000) Nuclear gamma-tubulin during acentriolar plant mitosis. Plant Cell 12: 433-442

Díaz J. F., Strobe R., Engelborghs Y., Souto A. A., Andreu J. M. (2000) Molecular recognition of Taxol by microtubules: Kinetics and thermodynamics of binding of Fluorescent Taxol derivatives to an exprosed site. J. Biol. Chem. 275: 265-276

Elmendorf G. H., Dawson C. S., McCaffery M. J. (2003) The cytoskeleton of Giardia lamblia. Int. J. Parasitol. 33: 3-28 
Evangelio J. A., Abal M., Barasoain I., Souto A. A., Lillo M. P., Acuña A. U., Amat-Guerri F., Andreu J. M. (1998) Fluorescent taxoids as probes of the microtubule cytoskeleton. Cytoskeleton 39: $73-90$

Fuller S. D., Gowen B. E., Reinsch S., Sawyer A., Buendia B., Wepf R., Karsenti E. (1995) The core of the mammalian centriole contains gamma-tubulin. Curr. Biol. 5: 1384-1393

Gaeritg J. (2000) Molecular mechanisms of microtubular organelle assembly in Tetrahymena. J. Eukaryot. Microbiol. 47: 185-190

$\mathrm{Gu}$ F. K. (1991) Introduction to protozoology. Higher Education Press, Peking.

Gu F. K., Zou S. F., Li Y. S., Ni B. (2003) Scanning electron microscopic observations on the ventral cortical cytoskeleton of Euplotes harpa (Protozoa, Ciliophora). Acta Zool. Sinica 49: 514-521

Iftode F., Clérot J. C., Levilliers N., Bré M. H. (2000) Tubulin polyglycylation: a morphogenetic marker in ciliates. Biol. Cell 92: 615-628

Iftode F., Fleury-Aubusson A. (2003) Structural inheritance in Paramecium: ultrastructural evidence for basal body and associated rootlets polarity transmission through binary fission. Biol. Cell 95: $39-51$

Kilburn C. L., Pearson C. G., Romijn P. E., Meehl J. B., Giddings T. H., Culver B. P., Yates J. R., Winey M. (2007) New Tetrahyme$n a$ basal body protein components identify basal body domain structure. J. Cell Biol. 178: 905-912

Klotz C., Ruiz F., Loubresse N. G. D., Wright M., Dupuid-Williams P., Beisson J. (2003) Gamma-tubulin and MTOCs in Paramecium. Protist 154: 193-209

Kovács P., Csaba G., Pállinger É., Czaker R. (2007) Effects of taxol treatment on the microtubular system and mitochondria of Tetrahymena. Cell Biol. Int. 31: 724-732

Lajoie-Mazenc I., Tollon Y., Detraves C., Julian M., Moisand A., Gueth-Hallonet C., Debec A., Salles-Passador I., Puget A., Mazarguil H. (1994) Recruitment of antigenic gamma-tubulin during mitosis in animal cells: presence of gamma-tubulin in the mitotic spindle. J. Cell Sci. 107: 2825-2837

Lechtreck F. K., Geimer S. (2000) Distribution of polyglutamylated tubulin in the flagellar apparatus of green flagellates. Cell Motil. Cytoskel. 47: 219-235

Liang A., Heckmann K. (1993) The macronuclear $\gamma$-tubulinencoding gene of Euplotes octocarinatus contains two introns and an in-frame TGA. Gene 136: 319-322

Liang A., Ruiz F., Heckmann K., Klotz C., Tollon Y., Beisson J., Wright M. (1996) Gamma-tubulin is permanently associated with basal bodies in ciliates. Eur. J. Cell Biol. 70: 331-338

Libusová L., Dráber P. (2006) Mutiple tubulin forms in ciliated protozoan Tetrymena and Paramecium species. Protoplasma 227: 65-76

Lou H. L., Gao W., Ni B., Gu F. K. (2007) Morphology and morphogenesis of the ciliature microtubular organelles in the ventral cortex of Paraurostyla weissei (Hyportrichida, Ciliophora). Acta Zool. Sinica 53: 742-749

Loubresse N. G. D., Riuz F., Beisson J., Klotz C. (2001) Role of delta-tubulin and the C-tubule in assembly of Paramecium basal bodies. BMC Cell Biol. 2: 1-7

Lynn D., Small E. B. (1981) Protist kinetids: Structual conservatism, kinetid structure, and ancestral states. Biosystems 14: 377-385
Marshall W. F., Rosenbaum J. L. (2003) Tubulin superfamily - Giving Birth to Triplets. Curr. Biol. 13: R55-R56

Marziale F., Pucciarelli S., Ballarini P., Melki R., Uzun A., Llyin V. A., Detrich H. W., Miceli C. (2008) Different roles of two $\gamma$-tubulin isotypes in the cytoskeleton of the Antarctic ciliate Euplotes focardii: Remodelling of interaction surfaces may enhance microtubule nucleation at low temperature. FEBS J. 275: 5367-5382

Moritz M., Braunfeld M. B., Sedat J. W., Alberts B., Agard D. A. (1995) Microtubule nucleation by $\gamma$-tubulin-containing rings in the centrosome. Nature 378: 638-640

Oakley C. E., Oakley B. R. (1989) Identification of a $\gamma$-tubulin, a new member of the tubulin superfamily encoded by mipA gene of Aspergillus nidulans. Nature 338: 662-664

Olins D. E., Olins A. L., Robert-Nicoud M., Jovin T. M., Wehland J., Weber K. (1989) Differential distribution of $\alpha$-tubulin isotypes in E. eurystomus determined by confocal immunofluorescence microscopy. Biol. Cell 66: 235-246

Oz S., Ivashkopachima Y., Gozes I. (2012). The ADNP derived peptide, NAP modulates the tubulin pool: implication for neurotrophic and neuroprotective activities. PloS One 7: 1411-1411

Ruiz F., Beisson J., Rossier J., Dupuis-Williams P. (1999) Basal body duplication in Paramecium requires $\gamma$-tubulin. Curr. Biol. 9: $43-46$

Sambrook J., Fritsch F., Maniatis T. (1992) Molecular Clone: a Laboratory Manual. Cold Spring Harbor Laboratory Press, New York, NY.

Scott V., Sherwin T., Gull K. (1997) Gamma-tubulin in Trypanosomes: Molecular characterization and location to multiple and diverse microtubule organizing centres. J. Cell Sci. 110: 157168

Shang Y. H., Li B., Gorovsky M. A. (2002) Tetrahymena thermophila contains a conventional $\gamma$-tubulin that is differentially required for the maintenance of different microtubule-organizing centers. J. Cell Biol. 158: 1195-1206

Sheng X., Zeng H., Zhang M., Yun M. X., Yin F., Gu F. K. (2011) Influences of the interference of the $\gamma$-tubulin gene expression on the morphology and microtubules of ciliate E. eurystomus. Zool. Sci. 28: 476-481

Shu H. B., Li Z., Palacios M. J., Li Q., Joshi H. C. (1995) A transient associated of gamma-tubulin at the midbody is required for the completion of cytokinesis during the mammaliam-cell division. J. Cell Sci. 108: 2955-2962

Tan M., Heckmann K. (1998) The two $\gamma$-tubulin-encoding genes of the ciliate Euplotes crassus differ in their sequences, codon usage, transcription initiation sites and poly (A) addition sites. Gene 210: 53-60

Zhou S. J., Yin F., Sheng X., Gu F. K. (2008) Morphology and morphogenesis of the ciliature microtubular organelles in the ventral cortex of Pseudourostyla cristata (Hyportrichida, Ciliophora). Acta Zool. Sinica 54: 299-308

Zhu H. (1984) The contractile vacuole. Bull Biol. 4: 3-5

Received on $14^{\text {th }}$ June, 2017; revised on $9^{\text {th }}$ September, 2017; accepted on $26^{\text {th }}$ September, 2017 